\title{
Unburned Carbon from Fly Ash for Mercury Adsorption: II. Adsorption Isotherms and Mechanisms
}

\author{
Z. Li, X. Sun, J. Luo and J. Y. Hwang \\ Institute of Materials Processing \\ J. C. Crittenden \\ Department of Environmental Engineering \\ Michigan Technological University, Houghton, Michigan 49931
}

\begin{abstract}
Adsorption behavior of unburned carbons from fly ash has been investigated in this study. Batch tests and column test were carried out for several unburned carbon samples from various ash sources and processing schemes. Adsorption isotherms have been obtained from these tests. Results show that the unburned carbons have equal or better adsorption capacity for elemental mercury comparing with some general purpose commercial activated carbons at low gas phase mercury concentration that is in the range of power plant emissions. Also it has been found that heat treatment of unburned carbon in the presence of air at $400^{\circ} \mathrm{C}$ enhanced the adsorption capacity, and the adsorption capacity decreased with the increase of the adsorption temperature. The mechanism of mercury adsorption on the unburned carbon was explained by the physical and chemical interaction between mercury and primary sites on the carbon surface.
\end{abstract}




\section{Introduction}

As mentioned in the previous paper, the mercury emissions from coalfired utility boilers has become a great concern due to the potential environmental threat to human health. ${ }^{[1]}$ In this regard, several technologies have been developed to remove mercury emitted during combustion of coals, and, among them, adsorption with activated carbon is a promising technology. ${ }^{[2-9]}$ As early as 1920s, Coolidge and Shiels proposed the use of activated carbon as the sorbent for mercury. ${ }^{[12,13]}$ With the evolution of the technology, carbon-type materials have become the primary sorbent in the field.

Currently, there are two major types of process configuration, i.e. fixed bed and carbon injection methods. ${ }^{[14]}$ In a fixed bed practice, the sorbent (e.g. activated carbon granulates) is packed in a column reactor and almost no flow or movement of sorbent is taking place inside the column. For the carbon injection method, fine carbon particles are spread into the flue gas stream, and adsorption is achieved during the flight of the carbon particles. Then the particles are collected by electrostatic precipitator (ESP) for regeneration or disposal. More recently, novel adsorbents such as sulfur impregnated activated carbon have emerged to enhance the efficiency of mercury removal from flue gas. ${ }^{[15,16]}$ However, due to the extremely high cost of these types of sorbent materials, full-scale industrial applications of these technologies have been impeded. Therefore, low cost adsorbent with sufficient adsorption capacity needs to be developed for the implementation of the mercury removal control technology.

Bergstrom studied the possibility of using fly ash to remove mercury from flue gas, and it has been found that $91 \%$ of the total mercury was removed with a fabric filter when additional fly ash was injected into the flue gas upstream of the filter. ${ }^{[17]}$ Recently, there are also several studies related to the adsorption of mercury by fly ash. ${ }^{[18-23]}$ They claimed that the mercury partitioning is directly related to the carbon content among individual ash samples. Our previous study showed that the mercury content in the unburned carbon separated from fly ash was significantly higher than that of the raw fly ash and the clean ash. ${ }^{[1]}$

One possibility for the high mercury content in the unburned carbon is due to its adsorbability. To understand the adsorption behaviors of the unburned carbon, this paper presents the results of adsorption tests for different carbons from fly ashes.

\section{Experimental Methods}

Material. Unburned carbons from six different fly ash sources were studied in this project. C1, C2 and C3 were the +100 mesh carbons from FA1, FA2, and FA3 fly ashes separated by the gravity separation followed by the electrostatic separation as described in the previous paper of the series. C1-F-L and C1-F-H were the -100 mesh carbons of FA1 fly ash separated by froth flotation. C1-F-L was dried in the air at $105^{\circ} \mathrm{C}$, whereas $\mathrm{C} 1-\mathrm{F}-\mathrm{H}$ was heated in the air at $400^{\circ} \mathrm{C}$ for 4 hours. Properties of these materials have been presented earlier. ${ }^{[1]}$ For comparison, two commercial activated carbons, BPL and F400 from Calgon Carbon Co. were also tested. 
Mercury source. A U-shaped mercury permeation tube (VICI Metronics) was used as the elemental mercury source. A thermal bath was used to maintain a constant temperature of the source. The carrier gas was nitrogen of P.P. grade (Interstate Welding Sales Co.). The VICI tube included a mercury-containing permeation tube in one leg and glass beads in the other leg to ensure a uniform heating of the carrier gas stream. The permeation rate of unit length of the tube is dependent on the temperature. By controlling the temperature of the thermal bath $\left(-2{ }^{\circ} \mathrm{C} \sim 70^{\circ} \mathrm{C}\right)$, various mercury concentrations of carrier gas can be obtained at a certain gas flow rate $(100 \mathrm{ml} / \mathrm{min} \sim 800 \mathrm{ml} / \mathrm{min})$. The permeation tube for this study was $4.0 \mathrm{~cm}$ long and had a releasing rate of approximately $300 \mathrm{ng} / \mathrm{min}$ at $70{ }^{\circ} \mathrm{C}$.

Mercury analysis. Mercury concentration in gas phase was analyzed with a gold film mercury vapor analyzer (JEROME 431-X, Arizona Instrument Corp.). The measuring range of the analyzer is 0.000 to $0.999 \mathrm{mg} / \mathrm{m}^{3}$, with a resolution of $0.001 \mathrm{mg} / \mathrm{m}^{3}$ and a sensitivity of $0.003 \mathrm{mg} / \mathrm{m}^{3}$. The precision is $5 \%$ relative standard deviation at 0.100 $\mathrm{mg} / \mathrm{m}^{3}$ and the accuracy is $+5 \%$ at $0.100 \mathrm{mg} / \mathrm{m}^{3}$. The maximum gas temperature is $40^{\circ} \mathrm{C}$. A measurement cycle takes 12 seconds with a gas flow rate of $750 \mathrm{ml} / \mathrm{min}$.

Setups and procedure. Batch tests were carried out with Tedlar sampling bags (231 series) purchased from SKC Co. According to the supplier, these Tedlar bags were made from chemically inert film. They had a low memory effect of previous samples and can be used in a wide temperature range $\left(-72^{\circ} \mathrm{C}\right.$ to $\left.107^{\circ} \mathrm{C}\right)$. They are strong, flexible and resistant to fatigue. In order to test the mercury permeability of these sample bags, the bags were filled with 9 liters of nitrogen gas with an initial mercury concentration of $0.418 \mathrm{mg} / \mathrm{m}^{3}$ and sealed right after filling. The mercury concentration was measured after 7 days at $0.409 \mathrm{mg} / \mathrm{m}^{3}$ and 0.399 after 14 days, corresponding to a reduction of $2 \%$ and $4.5 \%$ respectively. Therefore, the mercury permeability of such bags was very low.

The 231 Series sampling bags had two fittings, a hose/valve and a septum fitting. The hose/valve fitting was used for bag flushing, filling and sealing. The septum fitting had a syringe port on the top and was used for small amount sampling. The capacity of the bags was 10 liters.

Representative carbon samples were taken from the bulk materials and ground to pass a 200 -mesh sieve. The fine particles were dried in an oven at $105^{\circ} \mathrm{C}$ for 24 hours and stored in a desiccator for future use. The Tedlar bags were evacuated with a vacuum pump, and the desired amount of the dried carbon sample was put into the bag through the septum fitting. The carbon samples were weighed with a balance with an accuracy of $0.1 \mathrm{mg}$. The bag was then filled with the nitrogen gas with a mercury content of 450 $\mu \mathrm{g} / \mathrm{m}^{3}$ through the hose/valve fitting of the bag at a flow rate of $1 \mathrm{l} / \mathrm{min}$. The total volume of gas was controlled with a flow meter and a timer.

The filled bags were allowed to set for 7 days in order to reach equilibrium, and the equilibrium concentration of mercury was measured at the end of the 7 days. The amount of mercury being adsorbed was calculated according to the following equation: 
$\mathrm{Q}=\mathrm{V}\left(\mathrm{C}_{0}-\mathrm{C}_{\mathrm{eq}}\right) / \mathrm{m}$,

where $\mathrm{Q}$ is the amount of mercury adsorbed on the carbon $(\mathrm{mg} / \mathrm{g}), \mathrm{V}$ is the gas volume filled in the bag $\left(\mathrm{m}^{3}\right), \mathrm{C}_{0}$ is the initial mercury concentration of the gas $\left(\mathrm{mg} / \mathrm{m}^{3}\right), \mathrm{C}_{\mathrm{eq}}$ is the equilibrium mercury concentration of the gas $\left(\mathrm{mg} / \mathrm{m}^{3}\right)$, and $\mathrm{m}$ is the weight $(\mathrm{g})$ of the carbon sample put into the bag.

During the process of adsorption, the bags were periodically shaken to ensure uniform adsorption. For each test two concentration points were measured and the average value was reported. The measurements are within $5 \%$ of difference.

Column Tests. In order to investigate the kinetics of the adsorption process, column tests were carried out for the unburned carbon samples at various mercury concentrations of the carrier gas. The experimental apparatus is illustrated in Figure 1. Carbon samples were packed in a Ushaped tube with a diameter of $4 \mathrm{~mm}$ to form an adsorption bed. During the experiment, the carbon bed was placed in a thermal bath filled with antifreeze to maintain a constant temperature. The feed carrier gas line and the carbon bed were connected with a three-way valve, which allows the measurement of the mercury concentration of the feed gas prior to entering the bed. The mercury concentration analysis was carried out by sampling the carrier gas (either feed gas or exhaust gas) in a one-liter Tedlar bag and analyzed with the Jerome mercury vapor analyzer. For each packed bed, about 0.3 gram of unburned carbon sample was loaded, and glass wool was used as the supporting material. The column parameters are summarized in Table 1.

The total adsorption of mercury at equilibrium $\mathrm{q}$ was calculated by integration as shown in the following equation:

$q=\int_{0}^{Q_{t}}\left(C-C_{0}\right) d Q$

where $\mathrm{C}_{0}$ and $\mathrm{C}$ are the influent and effluent concentrations of mercury, and $\mathrm{Q}$ is the gas volume flowing into the bed at time $\mathrm{t}$.

\section{Results and discussion}

Adsorption of unburned carbons and commercial activated carbons. The batch adsorption tests indicated that the unburned carbons from fly ash had significant adsorption capacities for elemental mercury. Adsorption isotherms of these materials are presented in Figures 2-5. For the purpose of comparison, the isotherm of BPL activated carbon (Calgon Carbon Co.) is also shown in the figures. It can be seen from the plots that a concave type of isotherm is apparent for all the carbon samples. At low mercury concentration of the gas phase, the mercury adsorbed on carbon increased linearly with the increase of the gas phase mercury concentrations. When the gas phase mercury concentration reached a certain level $\left(>0.28 \sim 0.33 \mathrm{mg} / \mathrm{m}^{3}\right)$, the mercury adsorption increased rapidly with the gas phase mercury concentrations. It is noticed that the adsorption capacity of $\mathrm{C} 1$ and $\mathrm{C} 2$ carbons is higher than that of F-400 and BPL activated carbons at low gas phase mercury concentrations $\left(<0.3 \mathrm{mg} / \mathrm{m}^{3}\right)$. The order of mercury 
adsorption capacity from high to low is C1, C2, F-400, BPL, C3. For these unburned carbons the mercury adsorption capacity could be as high as $60 \mu \mathrm{g} / \mathrm{g}$. However, BPL activated carbon had a much higher capacity, up to $380 \mu \mathrm{g} / \mathrm{g}$, at a gas phase mercury concentration of $0.32 \mathrm{mg} / \mathrm{m}^{3}$. Since the mercury concentration in flue gas is in the range of 0.01 to $0.3 \mathrm{mg} / \mathrm{m}^{3}$, it can be seen from the above results that the unburned carbon is better suited for the mercury removal from flue gas.

Comparison of $\mathrm{C} 1$ carbons from different processes. Figure 6 presents the isotherms of $\mathrm{C} 1$ and $\mathrm{C} 1-\mathrm{F}$ carbon samples derived from different processing schemes. The $\mathrm{C} 1$ carbon was obtained by gravity separation followed by electrostatic separation as described in the previous paper, and it had a particle size of +100 mesh. The $\mathrm{C} 1-\mathrm{F}$ was the concentrate from froth flotation and had a size of -100 mesh. It can be seen that the isotherms of these two materials are basically the same with adsorption capacities very close to each other. This result indicated that the residual flotation reagents on the carbon surface had no or very little influence on the adsorption capacity of the unburned carbon. Also, it has been shown that the unburned carbon can be used as the adsorbent for elemental mercury, no matter the particle size and processing routes.

Effect of heat treatment on the adsorption capacity of $\mathbf{C} 1$ carbon. Figure 7 shows the isotherms of $\mathrm{C} 1$ carbon samples with or without heat treatment. Both samples were obtained from the same froth flotation process, but treated differently afterwards. The C1F-L sample was dried in air at $100^{\circ} \mathrm{C}$ for 4 hours while the $\mathrm{C} 1-\mathrm{F}-\mathrm{H}$ was heated in air at $400^{\circ} \mathrm{C}$ for 4 hours. It can be seen from the figure that the heat treatment had a significant impact on the adsorption capacity of the unburned carbon. The capacity was increased by about 4 times in the concentration range of $30 \mu \mathrm{g} / \mathrm{m}^{3}$ to $320 \mu \mathrm{g} / \mathrm{m}^{3}$, with a capacity up to $380 \mu \mathrm{g} / \mathrm{g}$. This improvement in adsorption capacity may be explained by the possibility that the heat treatment in air caused oxidation of the carbon surface; however, further investigation is needed to confirm the conjecture.

Effect of temperature on the adsorption capacity of $\mathbf{C 1}$ carbon. In order to investigate the effect of temperature, column tests have been carried out at two temperatures i.e. $20^{\circ}$ $\mathrm{C}$ and $40^{\circ} \mathrm{C}$. The carbon sample used for the tests was obtained from gravity separation followed by electrostatic separation, with a particle size of $48 \times 100$ mesh. The isotherms were derived by integration of a series of breakthrough curves (Figures 8-10). It can be seen from Figure 8 that the adsorption capacity at $40^{\circ} \mathrm{C}$ is lower than that at $20^{\circ} \mathrm{C}$. Compared with the capacity obtained in batch tests, the capacity in the column tests is much lower, less than $10 \%$ of that from the batch tests. This may be due to the difference in particle size and in adsorption time for the column and batch tests.

Mechanisms of mercury adsorption by unburned carbon. The adsorption of mercury on carbon can be explained by the physical and chemical interactions taking place between the carbon surface and mercury. According to the theory proposed by Dubinin, the carbon surface contains some adsorption centers, called primary sites. When a molecule of the adsorbate adsorbs on a primary site, the adsorbed molecule can then act as a secondary center for the adsorption of more molecules. ${ }^{[24]}$ 
The primary sites on the carbon surfaces investigated in this study could be any spots that have a high affinity for mercury molecules. By combination of the isotherms with the characterization data, these primary sites may be those enriched with oxygen-containing functional groups, minor/trace elements such as sulfur, and selenium and mercury, and catalyzing components. The enhancement of mercury adsorption after oxidizing unburned carbon at $400^{\circ} \mathrm{C}$ in air shows that oxygen-containing functional groups may have an important role, which is also suggested by Hall et al. ${ }^{[25]}$

\section{References}

1. Hwang, J.; Sun, X.; Li, Z. submitted to Environ. Sci. Technol.

2. Chang, R.; Offen, G. R. Power Eng. 1995, 99, 51-57.

3. Young, B. C.; Miller, S. J.; Laudal, D. L. Presented at the 1994 Pittsburgh Coal Conference, Pittsburgh, PA, Sep 1994.

4. Sinha, R. K.; Walker, P. L. Carbon 1972, 10, 754-756.

5. Matsumura, Y. Atoms. Environ. 1974, 8, 1321-1327.

6. Otani, Y.; Kanaoka, C.; Usui, C.; Matsui, S.; Emi, H. Environ. Sci. Technol. 1986, 20,735.

7. Otani, Y.; Emi, H.; Kanaoka, C.; Uchijima, I.; Nishino, H. Environ. Sci. Technol. 1988, 22, 708.

8. Meij, R. Water, Air, Soil Polut. 1991, 56, 21.

9. $\quad$ Chang, R.; Owens, D. EPRI J. 1994, July/Aug, 46.

10. Liberti, L.; Notarnicola, M.; Amicarelli, V.; Campanaro, V.; Roethel, F.; Swanson, L. Waste Mange. Res. 1998, 16, 2, 183-189.

11. Krishnan, S. V.; Gullett, B. K.; Jozewicz, W. E. Environ. Sci. Technol. 1994, 28, 1506-1512.

12. Coolidge, A. S. J. Am. Chem. Soc. 1927, 149, 949-1952.

13. Shiels, D. O. J. Phys. Chem. 1929, 33, 1398-1402.

14. EPA, , Mercury Study Report to Congress, 1997, EPA-452/R-97-10

15. Korpiel, J. A.; Vidic, R. D. Environ. Sci. Technol. 1997, 31, 2319-2325.

16. Liu, W.; Vidic, R. D.; Brown, T. D. Environ. Sci. Technol. 1998, 32, 531-538.

17. Bergstrom, J. G. T. Waste Mange. Res. 1986, 4, 57-64.

18. Hassett, D. J.; Eylands, K. E. Fuel, 1999, 78, 243-248.

19. Shannon D. Serre* and Geoffrey D. Silcox ; Adsorption of Elemental Mercury on the Residual Carbon in Coal Fly Ash, Industrial \& Engineering Chemistry Research; 2000; 39(6); 1723-1730.

20. Tanaporn Sakulpitakphon, James C. Hower,* Alan S. Trimble, William H. Schram, and Gerald A. Thomas; Mercury by Fly Ash: Study of the Combustion of a HighMercury Coal at a Utility Boiler, Energy \& Fuels; 2000; (3); 727-733.

21. James C. Hower,* M. Mercedes Maroto-Valer, Darrell N. Taulbee, and Tanaporn Sakulpitakphon ; Mercury Capture by Distinct Fly Ash Carbon Forms, Energy \& Fuels; 2000; 14(1); 224-226. 
22. James C. Hower,* Robert B. Finkelman, Robert F. Rathbone, and Jennifer Goodman; Intra- and Inter-unit Variation in Fly Ash Petrography and Mercury Adsorption: Examples from a Western Kentucky Power Station, Energy \& ; 2000; 14(1); 212-216.

23. P. Fermo, F. Cariati, S. Santacesaria, S. Bruni, M. Lasagni,\# M. Tettamanti,\# E. Collina,\# and D. Pitea*\# ; MSWI Fly Ash Native Carbon Thermal Degradation: A TG-FTIR Study, Environmental Science \& Technology; 2000;

24. Dubini, M.M., J.Phys. Chem. 1965, 39(6), 697-704

25. Hall, B.; Schager, P.; Weesmaa, J. Chemosphere, 1995, 30, 4, 611-627 
Table 1. Column Test Parameters

$\begin{array}{ll}\text { Bed inside diameter, } & 4 \mathrm{~mm}, \\ \text { Bed height (U-tube), } & \sim 16 \mathrm{~cm}, \\ \text { Carbon loading, } & \sim 0.3 \mathrm{~g}, \\ \text { Particle Size } & 48 \mathrm{X} 100 \mathrm{mesh} \\ \text { Height of the carbon particles, } & \sim 11.5 \mathrm{~cm}, \\ \text { Bath temperatures for carbon bed, } & 20^{\circ} \mathrm{C}, \\ \text { Mercury Source temperature, } & -2 \text { to } 70^{\circ} \mathrm{C}, \\ \text { Carrier gas }\left(\mathrm{N}_{2}\right) \text { flow rate, } & 100 \text { and } 200 \mathrm{ml} / \mathrm{min}, \\ \text { Carrier gas pressure, } & 20 \mathrm{psi}, \\ \text { Empty bed contact time, } & 0.87 \text { and } 0.43 \mathrm{~seconds}, \\ \text { Void coefficient, } & \sim 0.39, \\ \text { Gas superficial velocity, } & 13.27 \text { and } 26.54 \mathrm{~cm} / \mathrm{sec} .\end{array}$




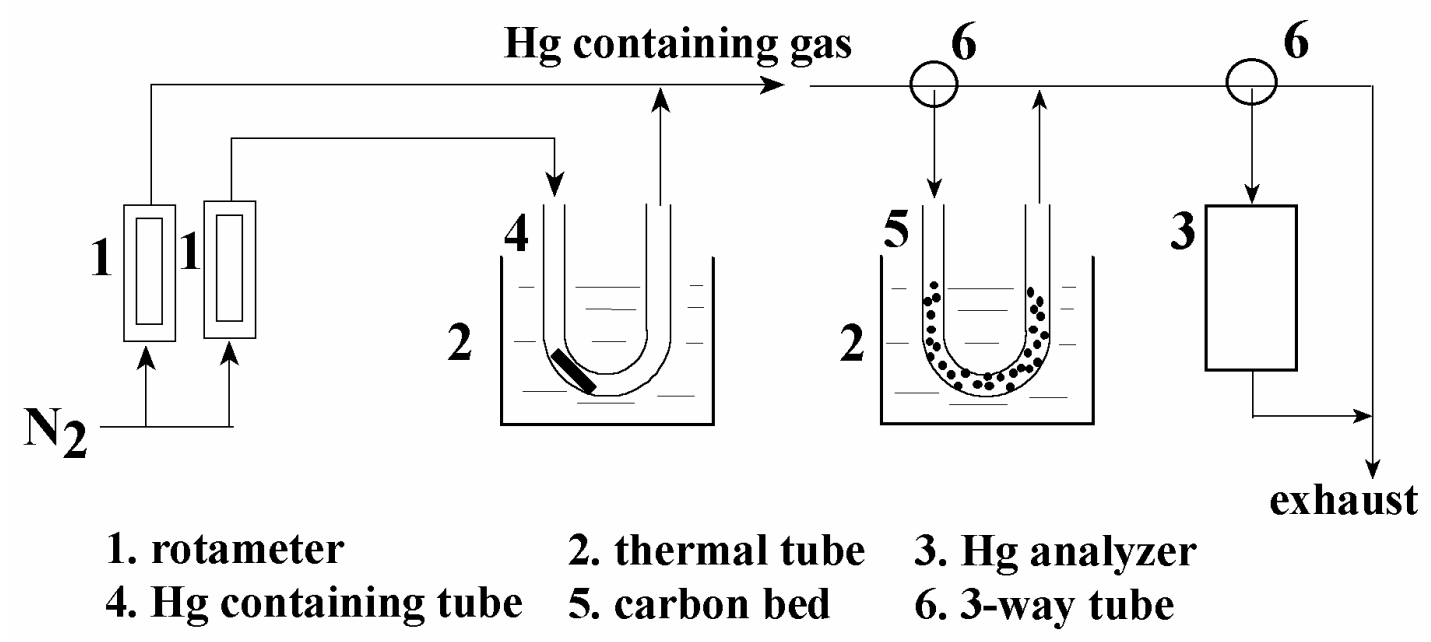

Figure 1. Schematic diagram of mercury vapor generation and column adsorption test apparatus 


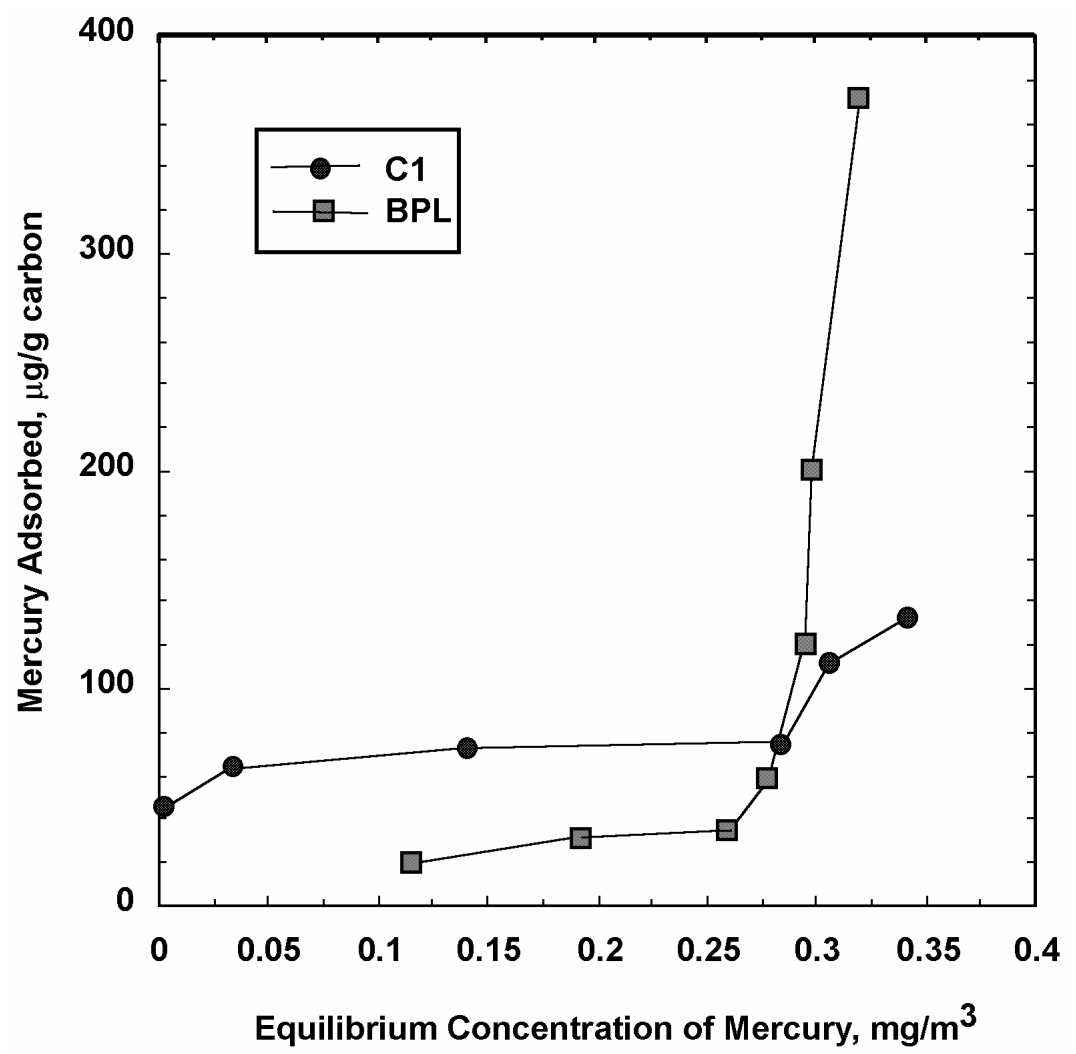

Figure 2. Adsorption isotherms of $\mathrm{C} 1$ and BPL carbons at $20^{\circ} \mathrm{C}$ 


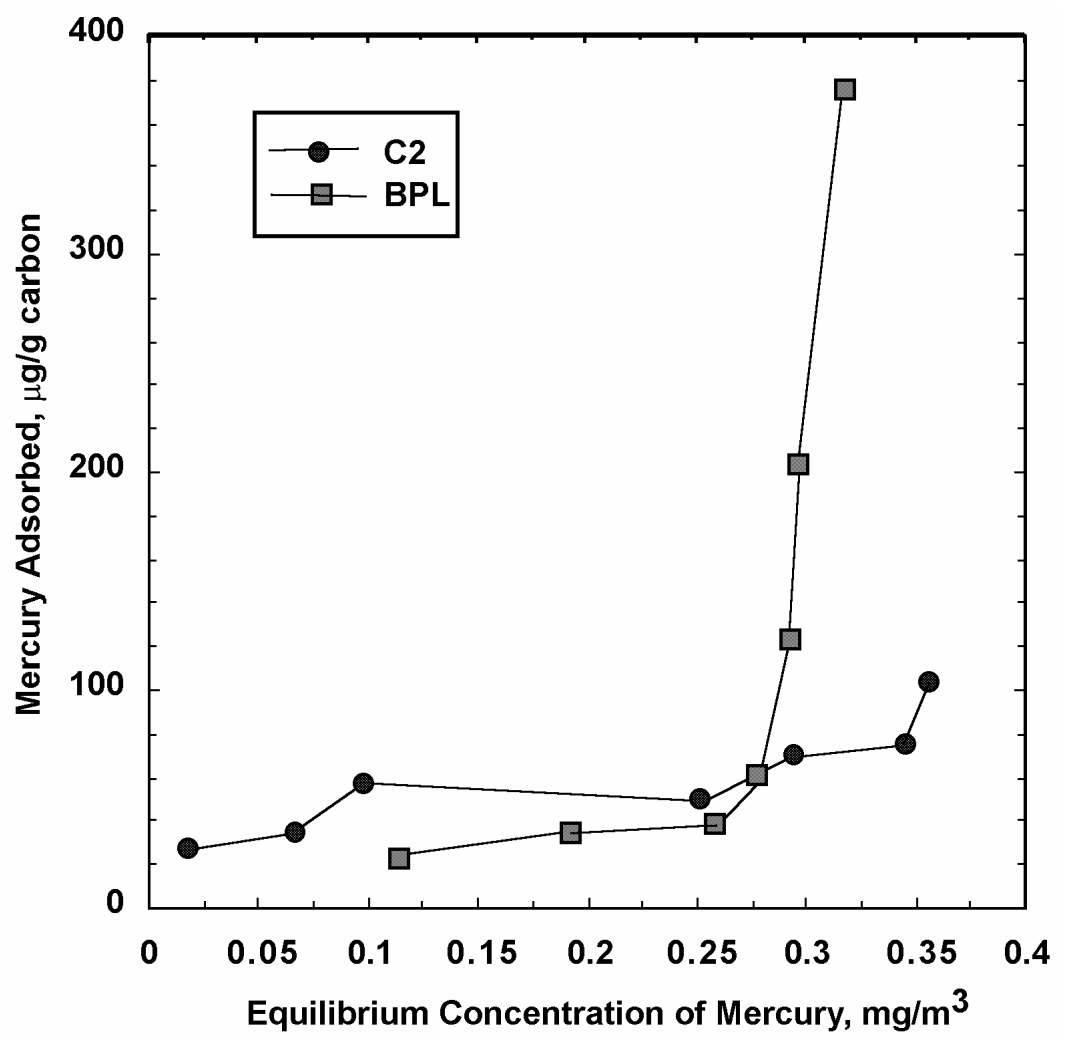

Figure 3. Adsorption isotherms of $\mathrm{C} 2$ and $\mathrm{BPL}$ carbons at $20^{\circ} \mathrm{C}$ 


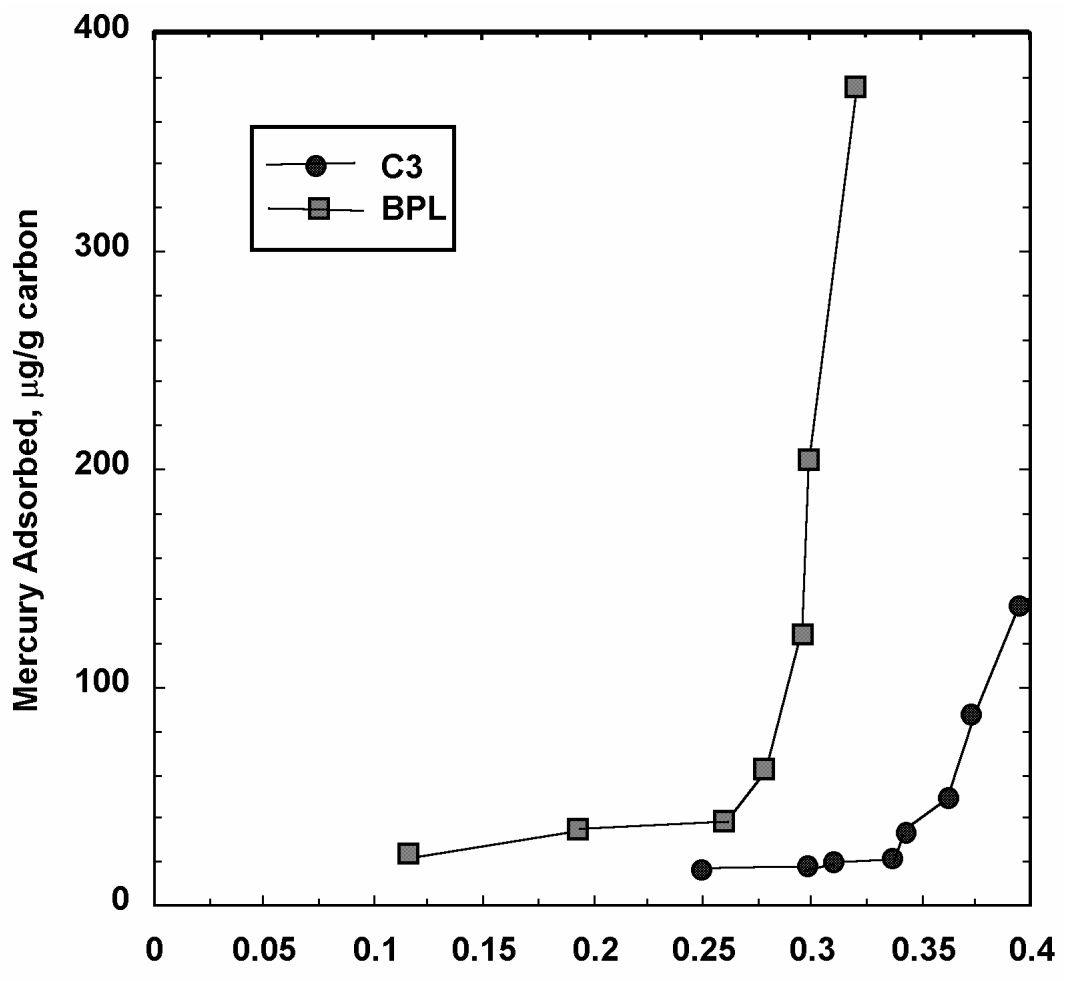

Equilibrium Concentration of Mercury, $\mathrm{mg} / \mathrm{m}^{3}$

Figure 4. Adsorption isotherms of $\mathrm{C} 3$ and $\mathrm{BPL}$ carbons at $20^{\circ} \mathrm{C}$ 


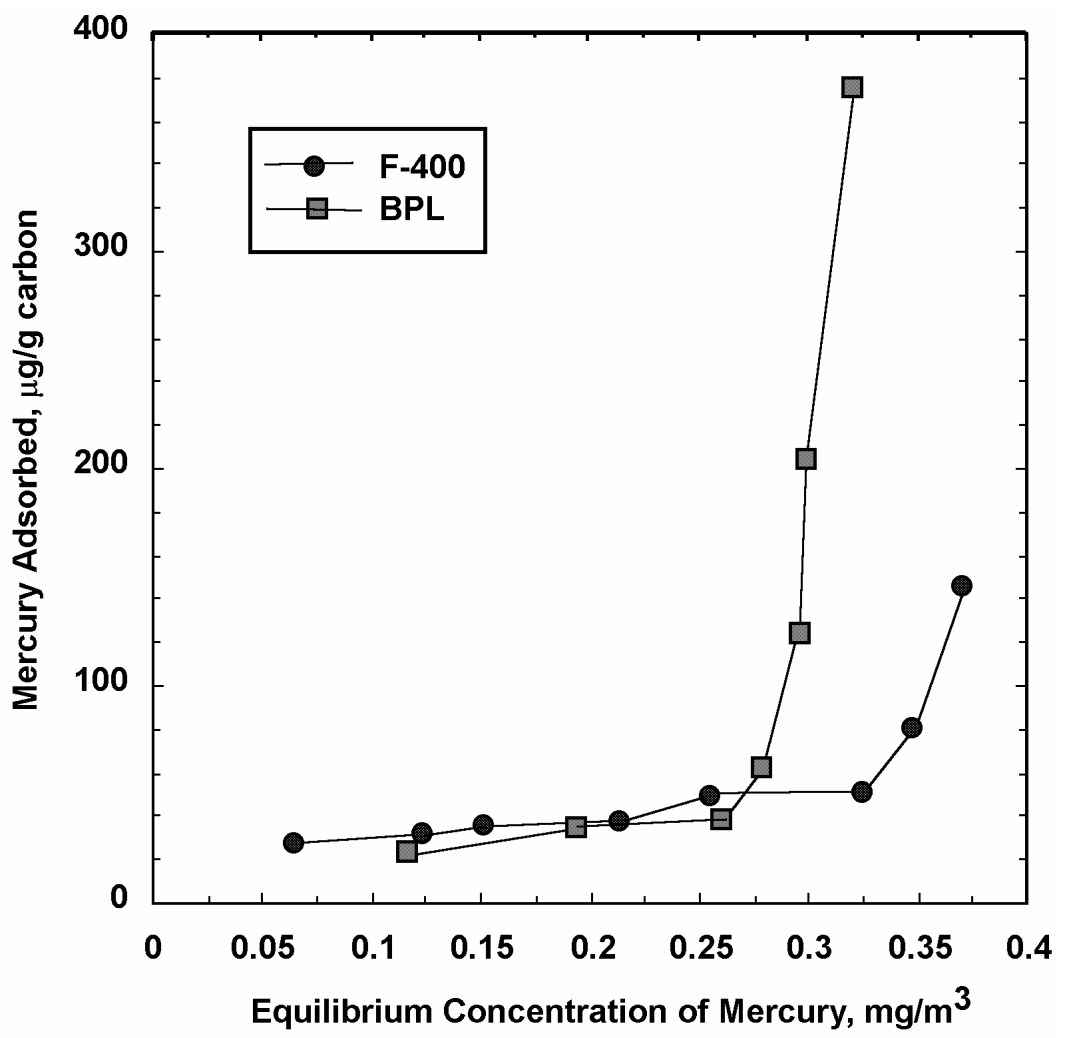

Figure 5. Adsorption isotherms of F-400 and BPL carbons at $20^{\circ} \mathrm{C}$ 


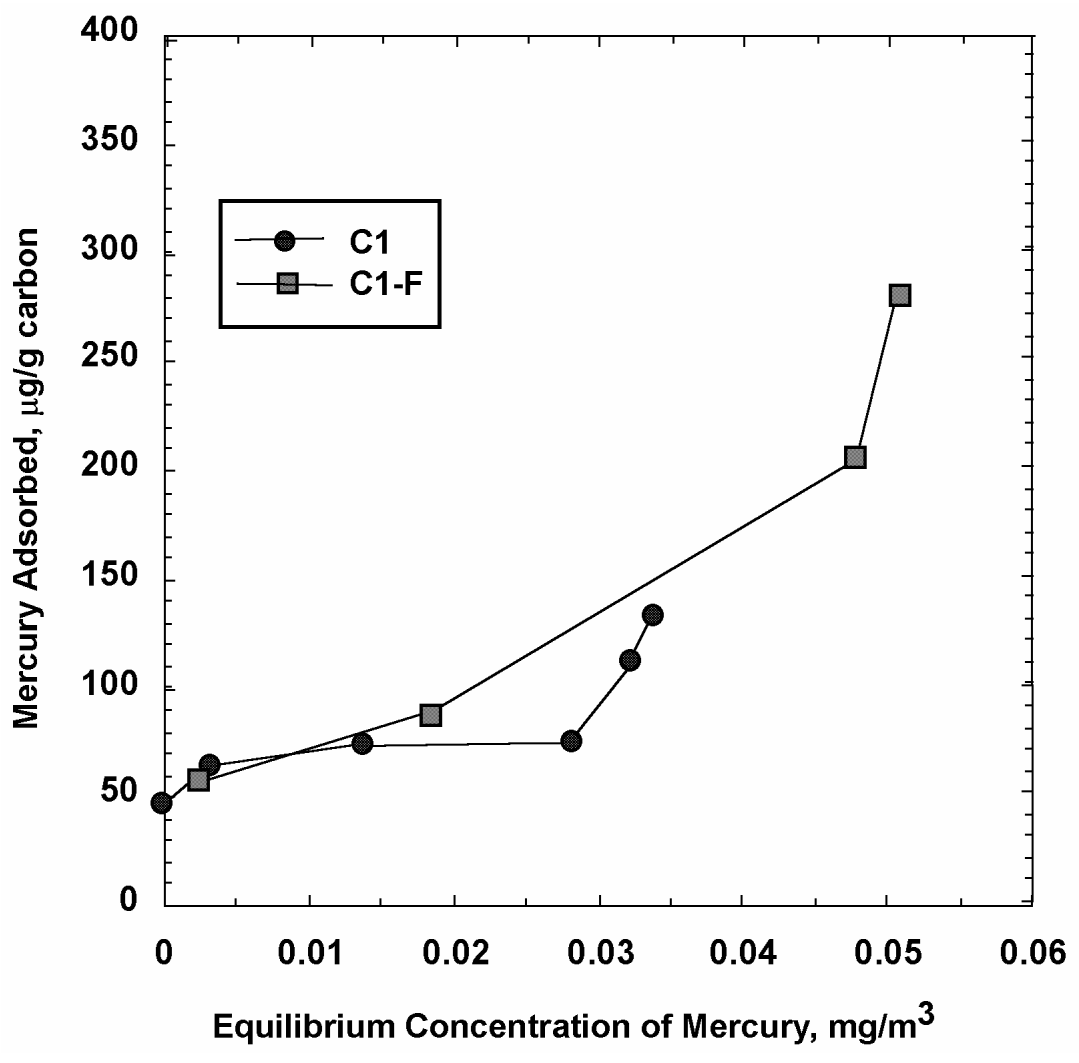

Figure 6. Adsorption isotherms of $\mathrm{C} 1$ carbons at $20^{\circ} \mathrm{C}$ 


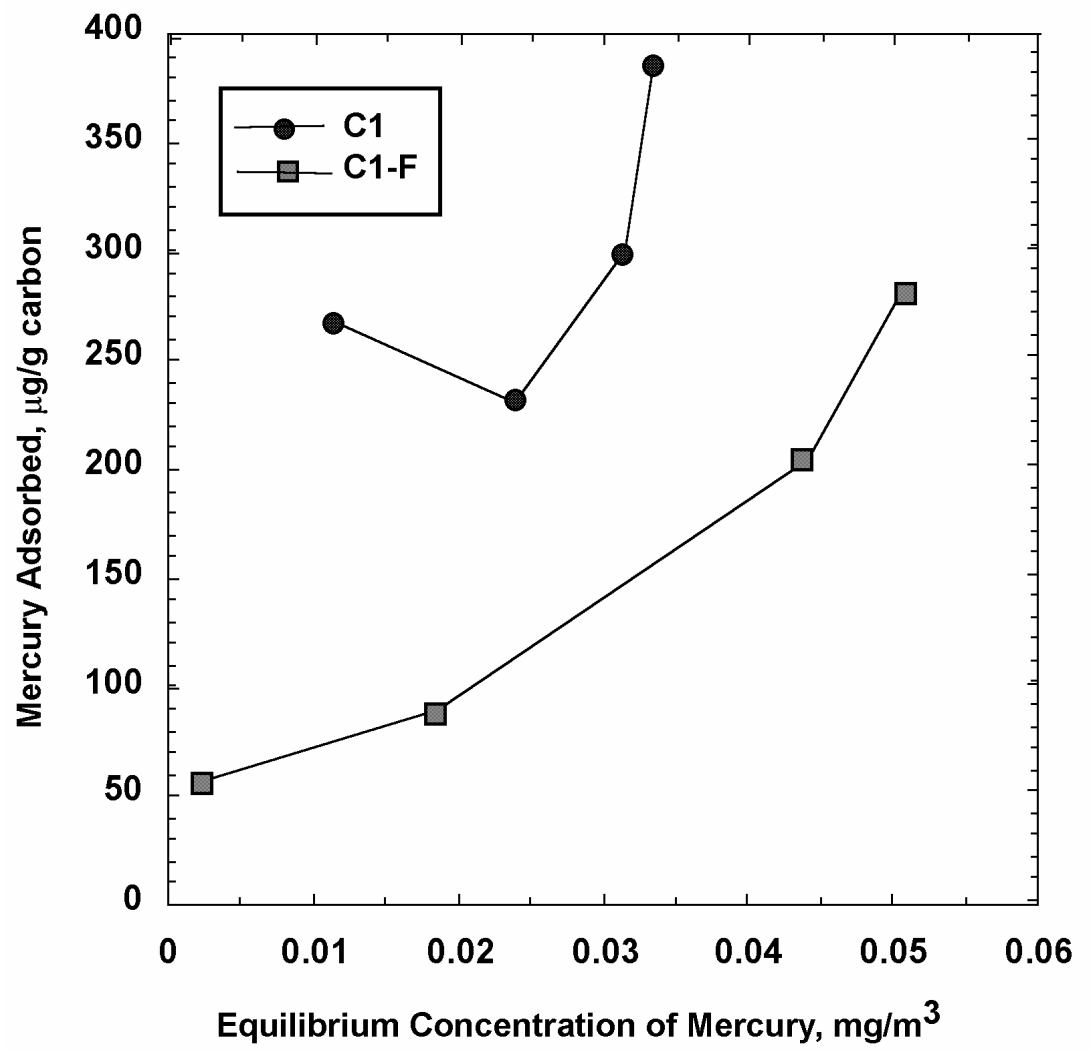

Figure 7. Adsorption isotherms of $\mathrm{C} 1$ carbon from flotation at $20^{\circ} \mathrm{C}$ 


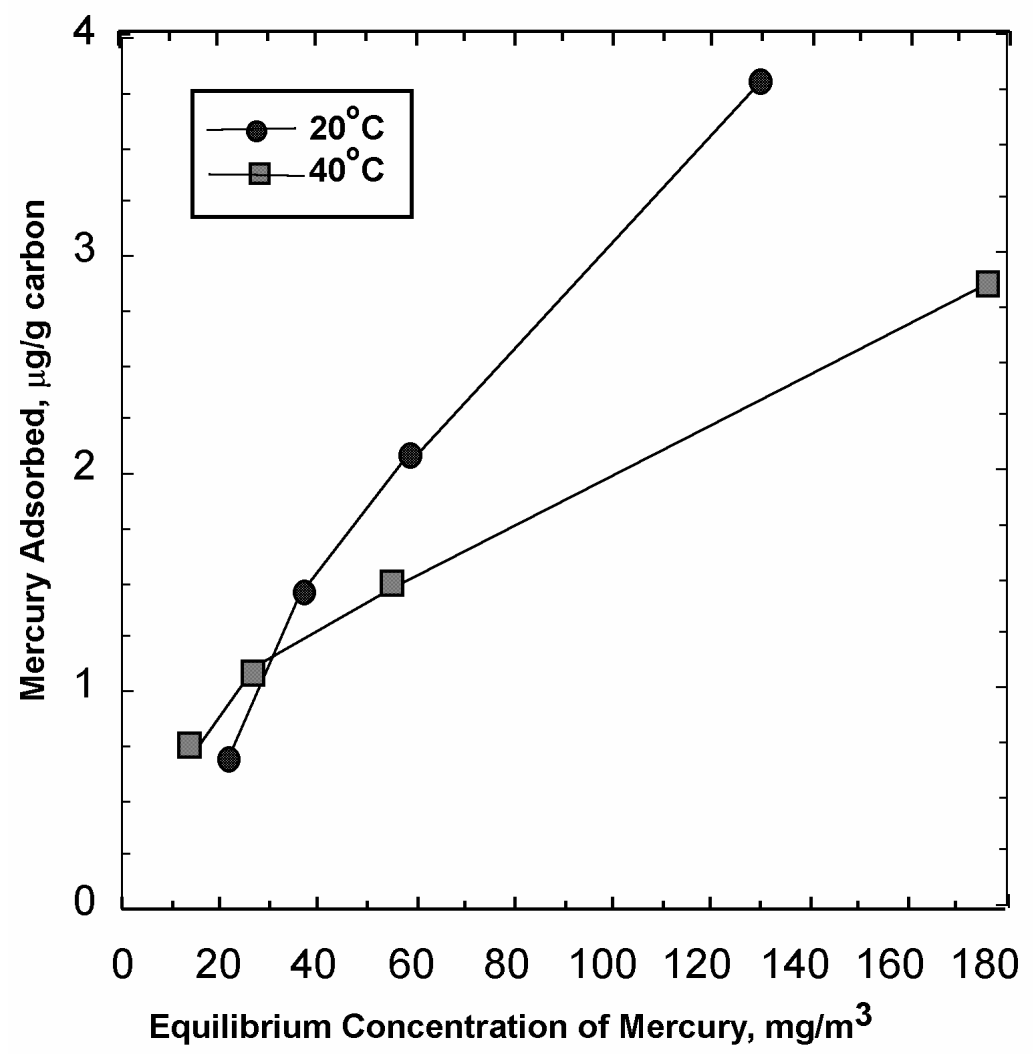

Figure 8. Adsorption isotherms of $\mathrm{C} 1$ carbons at $20^{\circ} \mathrm{C}$ and $40^{\circ} \mathrm{C}$ 


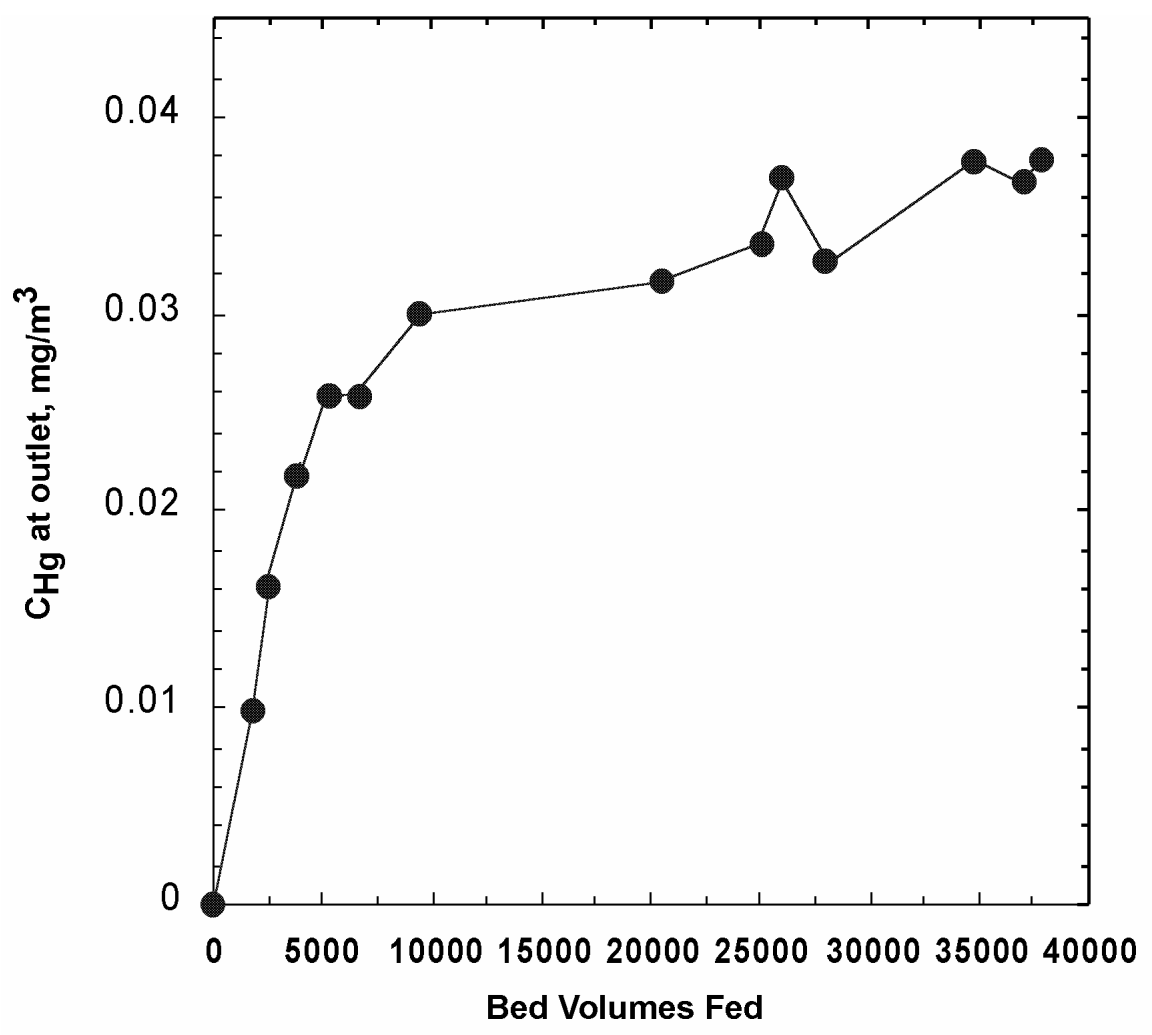

Figure 9. Breakthrough profile at $20^{\circ} \mathrm{C}, \mathrm{C} 1$ carbon, $\mathrm{C}_{0}=0.038 \mathrm{mg} / \mathrm{m}^{3}$ 


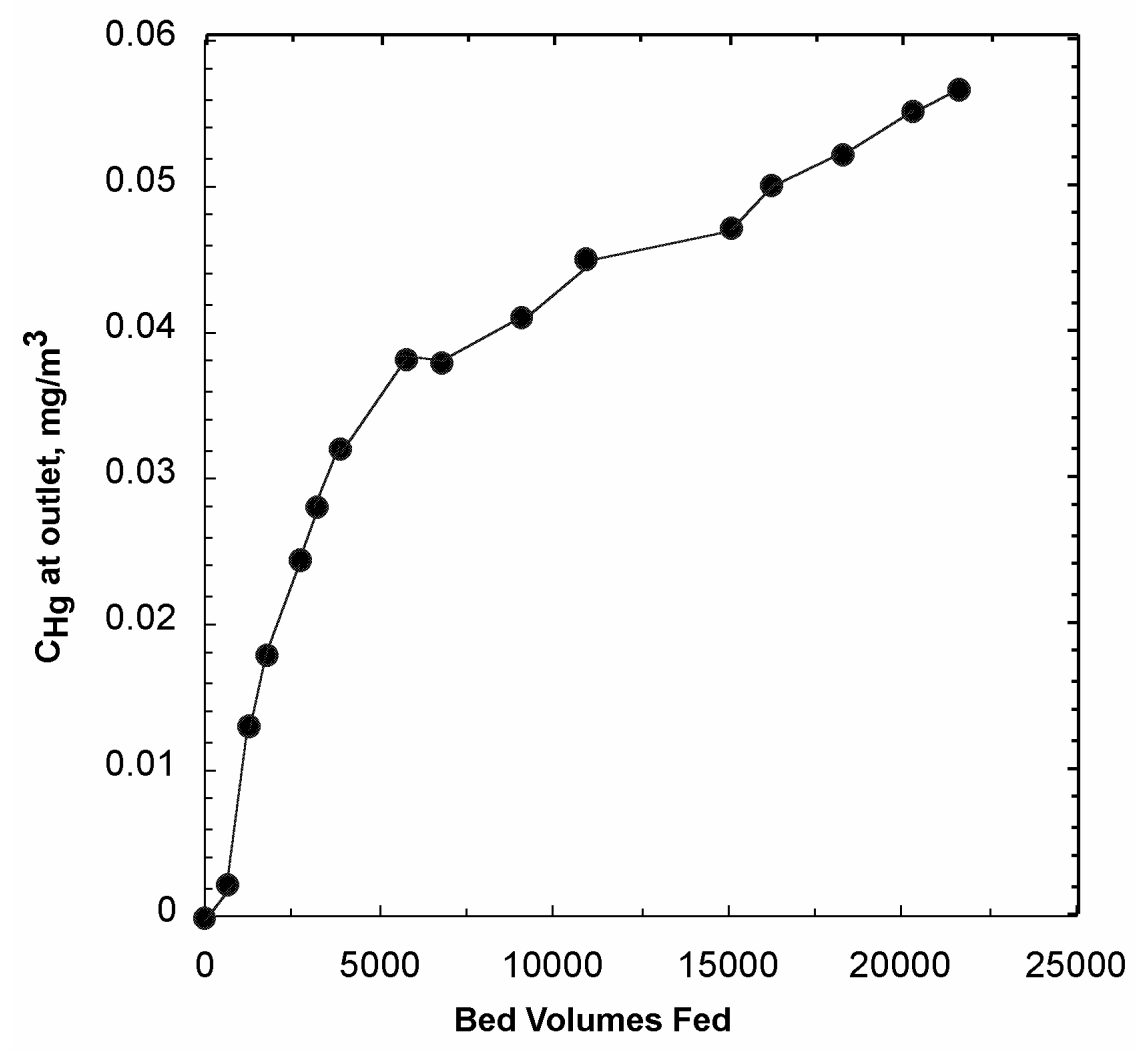

Figure 20. Breakthrough profile at $40^{\circ} \mathrm{C}, \mathrm{C} 1$ carbon, $\mathrm{C}_{0}=0.056 \mathrm{mg} / \mathrm{m}^{3}$ 